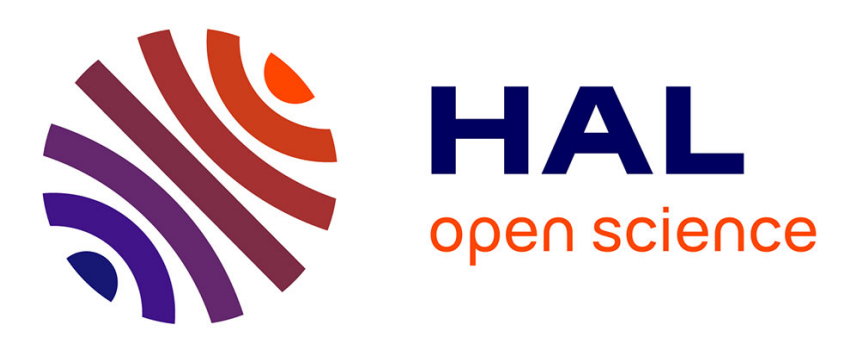

\title{
Rise and fall of elastic fibers from development to aging. Consequences on arterial structure-function and therapeutical perspectives
}

Wassim Fhayli, Quentin Boëté, Olfa Harki, Anne Briançon-Marjollet, Marie-Paule Jacob, Gilles Faury

\section{To cite this version:}

Wassim Fhayli, Quentin Boëté, Olfa Harki, Anne Briançon-Marjollet, Marie-Paule Jacob, et al.. Rise and fall of elastic fibers from development to aging. Consequences on arterial structure-function and therapeutical perspectives. Matrix Biology, 2019, 84, pp.41-56. 10.1016/j.matbio.2019.08.005 . hal-03431359

HAL Id: hal-03431359

https://hal.univ-grenoble-alpes.fr/hal-03431359

Submitted on 16 Nov 2021

HAL is a multi-disciplinary open access archive for the deposit and dissemination of scientific research documents, whether they are published or not. The documents may come from teaching and research institutions in France or abroad, or from public or private research centers.
L'archive ouverte pluridisciplinaire HAL, est destinée au dépôt et à la diffusion de documents scientifiques de niveau recherche, publiés ou non, émanant des établissements d'enseignement et de recherche français ou étrangers, des laboratoires publics ou privés. 


\section{Rise and fall of elastic fibers from development to aging. Consequences on arterial structure-function and therapeutical perspectives.}

Wassim Fhayli*@, Quentin Boëté*@, Olfa Harki*@, Anne Briançon-Marjollet ${ }^{@}$, Marie-Paule Jacob ${ }^{\$}$, Gilles Faury ${ }^{\circledR \#}$

* contributed equally

@ Univ. Grenoble Alpes, Inserm U1042, CHU Grenoble Alpes, HP2, 38000 Grenoble, France.

\$INSERM, U1148, and Hopital Bichat-Claude Bernard, 46 rue Henri Huchard, 75877 Paris, France.

\# corresponding author: Pr. Gilles Faury. Laboratoire HP2 - INSERM U1042 - Université Grenoble Alpes - Bâtiment Jean Roget - Facultés de Médecine et de Pharmacie Domaine de La Merci - 38706 La Tronche Cedex - FRANCE ; Tel: (33) 476637539 ; Fax: (33) 476637178 ; E-mail: Gilles.Faury@univ-grenoble-alpes.fr 


\section{ABSTRACT}

In the arteries of vertebrates, evolution has given rise to resilient macromolecular structures, elastin and elastic fibers, capable of sustaining an elevated blood pressure and smoothing the discontinuous blood flow and pressure generated by the heart. Elastic fibers are produced only during development and childhood, before being progressively degraded by mechanical stress and enzymatic activities during adulthood and aging. During this period, arterial elastic fiber calcification and loading of lipids also occur, all of these events conducting to arteriosclerosis. This leads to a progressive dysfunction of the large elastic arteries inducing elevated blood pressure as well as altered hemodynamics and organ perfusion, which induce more global malfunctions of the body during normal aging. Additionally, some arterial conditions occur more frequently with advancing age, such as atherosclerosis or aneurysms, which are called age-related diseases or pathological aging. The physiological or pathological degradation of elastic fibers and function of elastic arteries seemed to be rather inevitable over time. However, during the recent years, different molecules - including several ATP-dependent potassium channel openers - have been shown to re-induce elastin production and elastic fiber assembly, leading to improvements in the arterial structure and function or in organ perfusion. This review summarizes the changes in the arterial elastic fibers and structure from development until aging, and presents some of the potential pharmacotherapies leading to elastic fiber neosynthesis and arterial function improvement.

\section{KEYWORDS}

elastin - elastic fibers, arteries, signaling, biomechanics, development, aging 


\section{INTRODUCTION}

The extensible tissues, such as blood vessels, lungs and skin, contain elastic fibers which endow them with elasticity. The arteries are biological tubes, conducting blood from the heart to other organs. They have complex histological structures with varying functions, sizes and anatomical locations, although their walls are all composed of three layers, from the lumen to the exterior: the intima, media and adventitia. In the mature artery, the intima is mainly composed of endothelial cells (constituting the interface between the blood and the vascular wall) adhering to a basement membrane, a few fibroblasts, smooth muscle cells and sparse elastic fibers. The media is mainly made of smooth muscle cells interspersed with various amounts of elastic fibers or, in large arteries, nicely organized concentric elastic lamellae alternating with smooth muscle cell layers with sparse microfibrils and collagen fibers. The first elastic lamella, called the internal elastic lamina, separates the intima from the media, while the more external elastic lamella, called the external elastic lamina, separates the media from the adventitia, all the elastic lamellae accounting for elasticity and resistance to stretch of the wall $[1,2]$. Collagen fibers and fibroblasts are the major components of the adventitia, which also contains a few microfibrils and elastic fibers [3].

According to their distance from the heart and subsequent decreasing diameters, arteries are divided into large elastic arteries (the aorta and its proximal branches), medium-sized muscular arteries, and smaller distal arterioles [4]. Arteries, especially large arteries, have elastic properties related to their elastic fiber content (and organization) in the media, which decreases with the distance from the heart. The elastic fiber core consists of elastin (90\%), which is a polymer of the monomeric precursor tropoelastin and the dominant contributor to the elastic fiber property of elasticity, while the peripheral parts of the elastic fibers are made of fibrillin-rich microfibrils (10\%) [5-7]. Elastin and, to a lesser extent, microfibrils provide the elastic fibers and the large elastic arteries with elasticity [8-10], allowing for distention, storage of energy and stroke volume when distended during systole, then discharge of energy and stored blood volume when they return to their initial dimensions during 
diastole. This phenomenon, known as the Windkessel effect, helps to decrease the load on the heart and smoothens the arterial blood pressure and flow by minimizing the systolic flow and maximizing the diastolic flow in the arterioles [10-13].

Elastin is synthesized from the second half of gestation until the end of childhood, and the maximum elastin quantity in the body is reached before adulthood [12]. During vessel development, elastin and microfibrils are essentially synthesized by vascular smooth muscle cells (VSMC) to form the elastic fibers through complex multistep processes. In the large artery wall, the elastic fibers are then arranged into concentric elastic lamellae alternating with layers of circumferentially-oriented smooth muscle cells or are present in the interlamellar spaces, an elastic lamella and its adjacent VSMC layer forming a lamellar unit [14].

Elastic fibers are progressively altered by mechanical and enzymatic processes during adulthood and aging. Actually, several age-dependent mechanisms contribute to the arterial stiffening, including medial calcification and lipid deposition [15], as well as elastic fiber disruptions due to the increased activity of elastin-degrading enzymes, such as several matrix metalloproteases (MMP), including MMP-2 and MMP-9 [5,16]. As elastic fibers are gradually damaged, their load-bearing function is presumably taken over by collagen which renders the vessel wall less elastic and more rigid, as observed in the aging process [17]. The loss of elastin and elastic fibers leads to a decrease in the elastin/collagen ratio, resulting in increased arterial stiffness and decreased arterial distensibility [16]. Many studies have also shown that diabetes mellitus and arterial hypertension are important risk factors for functional and structural damages to the arterial wall, resulting in early arterial stiffening [18]. Increased arterial stiffness causes arterial wall wave reflections at the end of the systole rather than during diastole, which increase systolic and decrease diastolic blood pressures, thus increase pulse pressure [19]. The increase in systolic arterial blood pressure increases the systolic workload of the left ventricle (LV), leading to increased oxygen consumption of the heart, LV hypertrophy and interstitial fibrosis. All of these events related to the increase in arterial stiffness favor cardiovascular morbidity and mortality [20] and 
predispose to the development of aging-heart failure [21,22]. Arterial stiffness increases with age in both men and women, as measured by carotid to femoral pulse-wave velocity (PWV), a biomarker of arterial stiffness $[23,24]$, although vascular aging does not follow the same chronology in both sexes [25]. Prepuberal females present higher arterial stiffness than boys whereas, during their fertile years, females exhibit equal (central large elastic arteries) or lower (peripheral muscular arteries) arterial stiffness and reduced risk of cardiovascular disease, compared to males [26,27]. This female-related cardiovascular protection might be due to the presence of different isoforms of collagen and sex hormones - mainly estrogens [21]. Estrogens protect the endothelium by increasing endothelial nitric oxide synthase (eNOS) expression and NO production, and modulating prostacyclin and tromboxane A2 releases [25]. Later on, during the post-menopausal phase, female aortic distensibility declines sharply and becomes similar to that of males by the age of 60 , correlating with hypertension and increased cardiovascular risk in older women [27-30].

This review presents the major determinants of an appropriate structure and function of elastic fibers in large arteries during development and normal aging, as well as two major age-related vascular diseases, i.e. atherosclerosis and aneurysms. The perspective of pharmacotherapies aiming at repairing the damaged elastic fibers is also illustrated.

FROM DEVELOPMENT UNTIL MATURITY - ROLE OF ELASTIC FIBERS IN THE ARTERIAL STRUCTURE AND FUNCTION.

In mammals, the systemic blood pressure is regularly increasing with the developmental stage, from for instance in sheeps, rats or humans- a few $\mathrm{mmHg}$ during early gestation to several dozens of $\mathrm{mmHg}$ at birth, and around $100 \mathrm{mmHg}$ or above during adulthood [11]. On the contrary, the blood pressure in the pulmonary circulation decreases at birth from, for example in humans and pigs, a foetal blood 
pressure of 40-60 mm Hg, to 20-30 mmHg one day after birth and 10-15 $\mathrm{mm} \mathrm{Hg}$ a few days after birth and until adulthood [11].

In order to sustain these developmental blood pressure changes, which modify the mechanical stresses applied to the blood vessel and stimulating the vascular cells by mechanosensing / mechanotransduction [31], the arteries undergo a progressive remodeling throughout the developmental process, until adulthood. These changes include an increase in diameter and wall thickness of the systemic arteries [32] and, conversely, a decrease in wall thickness at birth regarding the pulmonary arteries [33].

During the development of most mammalians, transcription factors such as SOX7 trigger the constitution of the aorta [34], which is first an endothelium-based tube supported by extracellular matrix (ECM), before being surrounded by mesenchymal cells, myoblasts then smooth muscle cells, under the influence of major factors and pathways, including EphB/ephrin-B2 signaling [35]. Around midgestation, the elastogenic vascular cells (mainly VSMCs in the media) then produce microfibril-based fibers rich in fibrillins associated to numerous proteins which are important for the structure and function of these fibers. Arterial microfibril assembly requires fibronectin, integrins and heparan sulphate proteoglycans, and starts with the $\mathrm{N}$ - and C-terminal processing -by furin- of fibrillins, which then homotypically interact to form microfibrils. Microfibril-associated proteins, most of them presenting different isoforms, then bind to this initial structure, including in particular: latent TGF- $\beta$ binding proteins (LTBPs, implicated in microfibrilar latent TGF- $\beta$ sequestration), microfibrilassociated glycoproteins (MAGPs, participating to elastin deposition onto microfibrils and binding TGF- $\beta$ and fibronectin) and a disintegrin-like and metalloprotease (reprolysin-type) with thrombospondin type-I motif-like (ADAMTSL, involved at least in fibrillin-1 biogenesis, deposition or assembly) [7]. Some of these constituents are, however, not essential for elastic fiber assembly and function. It is the case for MAGP-1 and -2 , although they are more generally regulators of normal vascular development. and their mutation or deficiency is associated with arterial dilation/aneurysm [36]. Microfibril fibers possess elastic properties and are sufficient to smoothen the blood flow and 
pressure and bear the limited stress applied by a low blood pressure during early gestation [11]. However, they are unable to exert these functions under stresses of higher amplitude, when the blood pressure increases throughout the gestation. Therefore, during the last third of gestation and under the influence of different factors, including TGF- $\beta$ [37], VSMCs synthesize and secrete tropoelastin, the precursor of elastin. Tropoelastin is extracellularly assembled with microfibrils to form mature elastic fibers, which are able to accommodate the forces applied to the arterial wall by higher blood pressures $[6,7,12,38]$. After exportation, tropoelastin may bind to integrins, at least of the $\alpha_{\mathrm{v}} \beta_{3}$ type, and selfassociates to form microaggregates that are then cross-linked (between lysine residues) by lysyl oxydase (LOX). At this stage, fibulin-5 contributes to the limitation of the size of the microaggregates, while fibulin-4 allows for elastin cross-linking by LOX. The microaggregates are later deposited onto microfibrils, where they first align and self-assemble (through a reversible process called coalescence) before being cross-linked by LOX or lysyl oxidase-like-1 (LOXL1), which stabilizes the structure. Fibulin-5 is again involved in this process since it facilitates elastin microaggregate deposition onto microfibrils and, together with fibulin-4, elastin cross-linking. The completion of this step leads to stable and insoluble elastin polymers, which will be the major component of the mature elastic fiber, composed of an elastin core (90\%) surrounded by microfibrils (10\%) [7].

The major part of the elastic fibers are ultimately structured, in the arterial wall, into thicker concentric elastic lamellae before birth $[39,40]$, resembling in some ways to the elastic lamina present in the pleura of the developing lung [41]. The interplay between VSMCs and elastin/elastic fibers is of major importance in the arterial development since VSMCs produce elastin, which has been shown to be an important regulator of VSMC proliferation as well as intracellular (contractile components) and extracellular (migration) organization [42-44]. After birth, with the continuing augmentation of the blood pressure, elastin and, more slowly, collagen contents increase, together with elastic fiber thickness and the number of elastic lamellae [45]. Collagen I and elastin expressions peak during postnatal growth then return to low levels, while elastin content reaches a plateau before the end of growth 
$[6,12]$. Conversely, despite cell proliferation and because of the increase in elastin and collagen contents, the cellularity (= relative cell content) of the large artery wall decreases during the postnatal period [46-48].

The remodeling of the developing elastic artery wall results in a modification of its mechanical properties, which need to be adapted to the increasing blood pressure and, subsequently, the augmented forces applied to the wall, to permit an appropriate hemodynamics. For instance, the large arteries of the developing sheep are less distensible at low pressure, as compared to vessels from adults [46], whereas the wall thickness and stiffness increase from the prenatal life until adulthood at the corresponding physiological blood pressures or above. On the contrary, by comparison with the situation in the fetus, it has been shown in the pig that the pulmonary arteries become less distensible while their walls are thinning during the period following birth, concomitantly with the postnatal decrease in blood pressure [49].

All the structural components of the arterial wall and their organization account for the mechanical properties of the artery. The endothelial cells do not have a clear direct or structural role in the arterial mechanics. However, they indirectly impact the mechanical properties of the arteries through the secretion of different mediators which modulate the VSMC function. Besides regulating the contraction of VSMCs, therefore vasomotricity, endothelium-derived agents such as NO also stimulate the production of elastin by VSMCs, therefore impacting the arterial mechanics [50,51]. In resting conditions, VSMCs do not seem to account -as structural components- for much of the elastic properties of elastic and muscular arteries, except in the microcirculation [52-55]. However, they are able to regulate the arterial mechanics, resistance and capacity, through their ability to constrict $[52,54]$ as well as to produce and organize extracellular matrix components, like elastin and collagen [56].

Regarding the extracellular matrix components, the poorly distensible collagen fibers (elastic modulus, indicative of stiffness, $\sim 1 \mathrm{GPa}$ ) are a major contributor to the arterial wall mechanics. Their resilience and stiffness confer to the arterial wall their resistance to over-extension and therefore protects them 
against alterations at high strains [12,53]. Vascular microfibrils, mainly made of fibrillins - especially fibrillin-1 - [7], also play a role in the arterial wall mechanics. Their removal from the pig aorta induces stiffness reduction at low strain and increase at high strain [9]. Elastin is present in substantial amounts in the elastic fibers of the elastic lamellae and interlamellar spaces of the large artery walls ( $>50 \%$ of the proximal aorta dry weight), endowing them with elastic properties [12,57]. The elastic fiber can extend up to $\sim 140 \%$, with an elastic modulus of $\sim 0.4 \mathrm{MPa}[53,58], \sim 1000$ times lower than that of collagen fibers, while the lamellar unit, which is the functional unit of the wall from a mechanical point of view, presents a slightly higher elastic modulus of 0.5-0.7 MPa because of the minor contribution of VSMCs. The elastic fibers have been shown to impart a compressive stress on the collagen, the interplay between these two components explaining the mechanical properties of the composite arterial wall [59]. The mechanical properties of the elastic fibers and lamellar units below or in the physiological blood pressure range explain the ability of the large arteries to smoothen the blood pressure and flow by maintaining a high blood pressure during the diastole [53,60].

The number of concentric elastic lamellae/lamellar units in the arterial wall is also adapted to sustain the mechanical stress imposed by the blood pressure, to maintain the tension per lamella around 1-3 N.m ${ }^{-1}[14]$. Therefore, the number of elastic lamellae decreases downstream the vascular tree (from the elastic to the muscular arteries), when the blood pressure, vessel diameter and subsequent mechanical stress imposed to the arterial wall decrease. For instance, in the rat, 10-13 concentric lamellar units are present in the ascending aorta, 1-3 in the iliac-femoral arteries and 0 in smaller arteries [61]. It has also been shown that lamellar and interlamellar elastic fibers might contribute differentially to the arterial wall mechanical properties [57,62].

During adulthood, the elastic fibers exert their action despite progressive degradation by different enzymes, such as matrix metalloproteinases-2 and -9 (MMP-2 and MMP-9) [5], leading to the release of elastin peptides in tissues and the circulation [63]. These peptides bind to high affinity receptors in many cell types [64] and, in particular, trigger signals leading to intracellular calcium elevation in 
VSMCs and endothelial cells, and subsequent endothelium- and NO-dependent vasodilation [65-68]. Finally, genetic deficiency in the major components of elastic fibers results in discontinuous and irregular elastic fibers, as well as alterations of the arterial wall in mouse models and humans. In the arteries, genetic deficiency in elastin leads to VSMC proliferation, increased number of elastic lamellae and/or stenotic remodeling (Supravalvular aortic stenosis or Williams syndrome) [42,69-72] whereas deficiency in fibrillin-1 leads to aneurysmal pathologies (Marfan syndrome) [73,74].

\section{NORMAL ARTERIAL AGING AND ELASTIC FIBERS}

Age-related alterations of elastic fibers lead to impairments of the vessel mechanical properties and have profound effects on the morbidity and mortality in humans $[16,75,76]$.

Elastic fibers are extremely stable over time (elastin half-life of several decades) [77] and particularly resistant to chemical and physical attacks ( $\mathrm{pH}$ changes, heat, stretching) [78,79]. For these reasons, despite the end of their synthesis after adolescence and their slow alteration throughout adulthood and aging, elastic fibers can endow the arteries with some elasticity until an advanced age [30]. However, the high resistance of elastic fibers is not sufficient to ensure their optimal function throughout life, since the gradual deterioration of these fibers during normal aging progressively alters their elastic properties. Three main alteration mechanisms are involved:

I) The cyclic mechanical strain imposed over a lifetime by about 3 billions cardiac cycles induces a progressive accumulation of molecular ruptures which progressively modify the elastic fiber structure and lower its elasticity (arterial fatigue) [80],

II) The binding of several environmental factors (mainly glucose, lipids and calcium) over time modifies the molecular arrangement and interactions, and stiffens the elastic fibers [16]. The progressive calcification of the arterial wall elastin during aging [5] has a potentiating effect on the retention and fixation of cholesterol on the surface of elastic fibers. This contributes to the loss of 
elasticity of the arterial wall and constitutes an important risk factor involved in atherosclerosis and myocardial infarction [81,82]. Also, non-enzymatic glycation, during which glucose slowly and spontaneously reacts over time with the free $-\mathrm{NH}_{2}$ groups of the amino-acids, generates Advanced Glycation End products (AGEs) which bridge the residues, therefore altering the protein structurefunction. Also, AGE-mediated crosslinking between adjacent proteins leads to the lysis of elastic fibers and their replacement by other matrix components, especially collagen. This phenomenon, particularly affecting the proteins with a long half-life -such as collagen and elastin- which becomes more rigid, participates in the alteration of the cellular responses and leads to arterial stiffening [83-86]. Aging also increases the contents of Milk fat globule-EGF-8 (MFG-E8), a highly glycosylated protein, and its fragment, medin, in the arterial wall. Medin strongly binds to elastic fibers and induces elastolysis and amyloidosis in the arterial wall, affecting vascular elasticity and increasing stiffness and calcification [87].

III) The dysregulation of the balance between elastic fibers homeostasis and degradation [88]. Actually, elastin and the other components of elastic fibers can be degraded by elastase-type proteases belonging to different classes of proteolytic enzymes (matrix metalloproteinases - MMPs-, as well as serine-, cysteine- and aspartyl-proteases) whose syntheses and activations are modulated by many intrinsic and extrinsic factors $[77,88]$. In particular, the elastase activity is normally counterbalanced by the constitutive presence of inhibitors in the vascular wall, like the tissue inhibitors of metalloproteases (TIMPs), which limit the degradation of elastic fibers [89,90]. However, during aging, the progressive imbalance between proteases and protease inhibitors contributes to increased elastolysis in the arterial wall, inducing a decrease in the elastin/collagen ratio and rigidification [5]. Elastic fibers appear gradually disorganized, thinner and frequently fragmented, which leads to arterial enlargement under the influence of blood pressure as well as parietal thickening because of, at least in part, compensatory collagen production, and decreased elasticity [62,88,91-93]. 
Furthermore, the degradation of elastin releases elastin peptides, some of them reaching the circulation and being measurable in the serum [63]. Elastin peptides are able to induce multiple biological effects on various cellular targets through their binding to the elastin receptor complex (ERC) [64,94], such as vasodilation when binding to the endothelial ERC $[66-68,95]$. The number of these receptors does not vary with age [96], but a decoupling of some of their downstream signaling pathways progressively occurs during aging [97]. This phenomenon also contributes to the alteration of the vascular functions, in particular vasomotricity [98] as well as modulation by the extracellular glucose level of calcium homeostasis- and/or NO-related vasodilation and signaling pathways [99]. Nevertheless, during aging, the activation of ERC by elastin peptide continues to trigger the production of elastase and free radicals, enhancing the alteration of the tissues $[97,100]$.

All the above-described age-related changes in the arterial structure, called arteriosclerosis, increase the heart afterload, therefore heart work, and result in left ventricular hypertrophy, possibly fatigue and ultimately failure, in parallel to chronic ischemia of the peripheral tissues, causing a progressive deterioration of the organic functions $[80,81,101]$. These features of normal cardiovascular aging are rather universal, although a change in the initial availability of the elastic fiber component could modify some main consequences of physiological aging or lead to alternative aging. For instance, mice presenting an heterozygous deletion in the fibrillin-1 gene (Fib-1 $+/ \mathrm{mg} \Delta$ ) undergo premature aortic aging, including decreased elastin/collagen ratio and increased stiffness [102]. Also, surprisingly, heterozygous mice genetically deficient for elastin (Eln+/-) exhibit some signs of premature aging in adults, such as early increased aortic stiffness, together with the absence -in aged animals- of some other main features of aging, such as aorta wall thickening [103].

Besides normal aging, some deleterious arterial changes appear more frequently with age in some individuals of a given species only, under the influence of environmental factors or genetic predisposition. Two of these age-related diseases will be presented below. 


\section{ALTERATION OF ELASTIC FIBER STRUCTURE AND FUNCTION DURING PATHOLOGICAL AGING OF ARTERIES: THE EXAMPLES OF ATHEROSCLEROSIS AND ANEURYSMS AS MAJOR AGE-RELATED DISEASES.}

Aging is considered as an evident risk factor of cardiovascular diseases due to the physiological alteration of the arterial structure. However, some people are more susceptible to the occurrence of additional arterial or venous diseases in an early "chronological" age [104]. The existence of such a pathological vascular aging suggests that there is a dissociation between biological and chronological age of vessels. In some patients, an "early vascular aging" (EVA) could take place because of genetic defects or exposure, at an early age, to environmental events triggering oxidative stress and inflammation $[105,106]$. Multiple blood vessel pathologies which present a serious public health problem are related to elastic fiber degradation and have a prevalence / incidence which is clearly increasing with age, such as varicose veins [107], aneurysms [108-110], and atherosclerosis [111], the latter being a major cause of coronary disease and stroke [112]. These two atherosclerosis-related cardiovascular diseases, involving substantial elastic fiber degradation, are the first and third causes of death worldwide, respectively. They nearly cause 250 deaths/100,000 persons/year, which is about $85 \%$ of cardiovascular and $28 \%$ of total mortality [111]. Aneurysms are caused by elastic fiber degradation and are a major threat to life, i.e. the 18th cause of death in the general population (15th cause of death in people older than 65) in the USA, with about 3 fatal ruptured aneurysms per 100,000 persons per year [110] Because of their important morbidities, increased occurrence and aggravation during aging, severe impact on public health and close relation to arterial elastic fiber degradation, atherosclerosis and aneurysms will be further described in the following sections.

\section{Atherosclerosis}


Atherosclerosis is characterized by the formation, in large and medium-sized arteries, of plaques composed of lipids, calcified regions, immune and foam cells, together with vascular smooth muscle and endothelial cells. Plaque formation starts with circulating LDL-cholesterol diffusion and accumulation in the arterial wall, due to endothelial dysfunction. These lipids are oxidized and subsequently stimulate vascular inflammation and monocyte recruitment in the vascular wall. The monocytes then load the oxidized lipids to form foam cells. Further, accumulation of necrotic debris and ECM components, together with VSMC migration and formation of a fibrous cap, cause the plaque progression. Ultimately, under the influence of the forces applied by the blood flow, plaques can rupture, resulting in thrombus formation and clinical manifestations such as tissue hypoxia and acute ischemic events (e.g. myocardial infarction and stroke) [113]. Conversely, intermittent hypoxia, the major consequence of obstructive sleep apnea, induces oxidative stress elevation, sympathetic activation and inflammation, which favor endothelial dysfunction, elastic fiber disorganization, hypertension and atherosclerosis [114,115]. Structural and physiological changes related to aging of the arterial wall also predispose to or favor atherosclerosis. Some of these major modifications are inflammation, oxidative stress, endothelial dysfunction, formation of collagen bridges, disorganization of elastic fibers and decrease in the elastin/collagen ratio [106,116-118].

The most described event involving the elastic fibers in atherosclerosis is the alteration of the elastin/collagen ratio, due to elastic fiber degradation under the atheroma plaque by elevated elastasetype protease levels [119]. Also, age related-interlamellar collagen accumulation and -elastin association with insoluble fibrillar material promote arterial stiffening [92], the intimal rigidification inducing a disruption of endothelial barrier integrity and increasing endothelial permeability. This enhances the transmigration of inflammatory molecules, monocytes and lipids, promoting the development of atherosclerotic lesions [120]. Besides, collagen I, a prominent participant to the aging processes, seems to be involved in endothelial dysfunction, by decreasing NO synthesis [121], as well as in leukocytes recruitment, by increasing SMC expression of vascular cell adhesion molecule 
(VCAM)-1 [122]. Furthermore, elastin peptides released during age-related elastolysis by overactive elastases could initiate atherogenesis process through several mechanisms. They modulate intracellular calcium level and NO liberation in endothelial cells, promote LDL oxidation, monocyte and leucocyte recruitment through a chemoattractive effect, and modulate the differentiation of lymphocytes present in the plaques $[94,123,124]$. In parallel, tropoelastin is re-expressed and accumulates in atheroma plaques, and has recently been suggested to be a biomarker for atherosclerotic plaque progression and instability [125]. Finally, in the context of the atherosclerotic plaque, the combined stimulations of VSMCs by disturbed hemodynamic forces applied to the wall, oxidized LDLs and proinflammatory molecules such as IL-1 $\beta$ and TNF- $\alpha$ induce a phenotypic switch of these cells, from quiescent and contractile to a dedifferentiated proliferative, proinflammatory, migratory and synthetic state. VSMCs then produce different ECM proteins as well as tissue inhibitor of MMP (TIMP) and MMPs, including MMP-2 and MMP-9. The inflammatory cells present in the plaque also produces MMPs and other elastases which, together with the MMPs released by VSMCs, contribute to the remodelling of the extracellular matrix, including elastic fiber degradation [126,127]. The age-related activation of MMP2 and MMP-9, two key enzymes that enhance the destabilization of atheromatous plaques, is a major aggravating factor for atherosclerosis progression $[128,129]$.

\section{Aneurysms}

An aneurysm is a permanent and localized dilation of an artery presenting at least a $50 \%$ increase in diameter compared to the expected normal diameter of the artery [130]. In the large elastic arteries, abdominal aorta aneurysm (AAA) is much more common than thoracic aorta aneurysm (TAA), the prevalence of AAA being $0-5 \%$ in females, and between $1-12 \%$ in males [109]. The associated mortality is high due to aneurysm rupture and subsequent hemorrhage [131], the mortality rate of ruptured AAA being five times higher than that of ruptured TAA [110]. TAAs are often caused by rare gene mutations (see below) with an occurrence early in life (30\% of all cases), sporadic with an 
occurrence increased with aging, or associated with bicuspid aortic valves. The etiology of AAAs, occurring mostly in later life, is related to both environmental factors (smoking habit, older age, male gender, coronary heart disease, hyperlipidemia, hypertension and chronic obstructive pulmonary disease (COPD)) and familial genetic factors different from the rare gene mutations cited for TAAs $[132,133]$.

An aneurysm is not a simple passive dilation, it is rather resulting from an active multifactorial process whose development is triggered by a dynamic wall remodeling. This involves inflammation, oxidative stress, VSMC apoptosis or switch from the differentiated contractile state to an undifferentiated synthetic state. In TAAs, the TGF-b stimulation of VSMCs enhances the synthesis of fibrillar ECM, antiproteases, proteases (such as MMP-9) as well as clearance of protease/antiprotease complexes. In AAAs, switched VSMCs also secrete MMPs (such as MMP-2 and -9) whose proteolytic activities are combined with those from MMPs and other elastolytic proteases secreted by immune cells (leukocyte elastase) or exfiltrated from the circulation (plasmin, MMP-8, MMP-9) [132-135]. The changes in VSMC synthesis of ECM and the proteases present in the aneurysmal wall induce major extracellular matrix modifications, which include elevated collagen deposition and an extensive destruction of elastic fibers [136,137]. MMPs activation, in particular of MMP-2, MMP-9 and MMP-12, induces substantial elastic fiber degradation in aneurysmal aortic tissues [136] and other organs, such as the emphysematous lung [138]. Aneurysmal regions of the artery present a wall stiffening which results from early ECM disorganization, including elastin and elastic fiber damage, enhanced collagen deposition and disruption of elastin-contractile units. However, the wall elastic modulus (i.e. stiffness) in arterial aneurysms decreases with age [139]. These structural modifications of the arterial wall seem to precede the aneurysmal dilation $[137,140,141]$ and are enhanced by aging, which explains the significant influence of age on aneurysm risk [139,142,143], in addition to genetic predisposition [141]. In particular, genetic deficiencies in some microfibril components have been linked to altered elastic fibers and aneurysmal syndromes, especially TAA in the ascending aorta. For instance, patients with 
Marfan syndrome -caused by mutations in fibrillin-1 [7,74]- and mice genetically altered for the fibrillin-1 gene develop ascending aorta aneurysms, which even worsen during aging [74,102,144]. Similar aneurysms have also been found in syndromes involving mutations in other microfibril components, such as fibulin-4 or LTBP-4 (cutis laxa), or elastic fiber assembly-related molecules such as LOX, while the corresponding murine models feature similar arterial aneurysms [145-148]. Thoracic aneurysmal pathologies has also been linked to abnormalities in TGF- $\beta$ signalling, including mutations in the TGF- $\beta 2$ (TGFB2), TGF- $\beta 3$ (TGFB3), TGF- $\beta$ receptor 1 (TGFR1) and TGF- $\beta$ receptor 2 (TGFBR2) (Loeys-Dietz syndrome) [147]. Because microfibrils are a TGF- $\beta$ reservoir, the occurrence of aneurysms in humans or mice presenting mutations in microfibrilar components, therefore microfibrilar abnormalities, may be due to a dysregulation of TGF- $\beta$ signalling. However, a recent work has shown that mice genetically deficient for fibrillin-1 $\left(\mathrm{Fbn} 1^{\mathrm{C} 1039 \mathrm{G} /+}\right)$ present thoracic aorta aneurysms that are unrelated to TGF- $\beta$ signaling, which indicates that the onset of thoracic aorta aneurysms might have more complex origins [149].

\section{PHARMACOLOGICAL REINITIATION OF ELASTIN OR ELASTIC FIBER SYNTHESIS IN AGED PATIENTS OR ANIMALS}

The challenge of restoring or increasing the elastic fiber content in aged patients or animals (or in pathological conditions) is of particular importance and consists in stimulating the production of the elastic fiber components at a time when the synthesis of several of them is very low.

Tropoelastin, the soluble precursor of elastin, and other elastic fiber components are synthesized in the skin by dermal fibroblasts and in vessels by medial VSMCs. The synthesis of tropoelastin is regulated by numerous chemokines and growth factors $[150]$ and also by potassium $\left(\mathrm{K}^{+}\right)$and calcium $\left(\mathrm{Ca}^{2+}\right)$ ions. Indeed, $\mathrm{K}^{+}$excess in the extracellular medium induces the depolarization of the plasma membrane, which causes the opening of voltage-dependent calcium channels $(\mathrm{CaV})$ and leads to an increase in $\left[\mathrm{Ca}^{2+}\right]_{\mathrm{i}}$ and a decrease in elastin synthesis $[151,152]$. Such a decrease in elastin synthesis was also 
shown in VSMCs incubated with the calcium ionophore A23187, which trigger $\mathrm{Ca}^{2+}$ influx and $\left[\mathrm{Ca}^{2+}\right]_{\mathrm{i}}$ elevation $[152,153]$. On the contrary, $\mathrm{K}^{+}$efflux from cells leads to an increase in elastin synthesis due to membrane hyperpolarization and $\mathrm{CaV}$ closing. This has been shown in experiments using the ATPdependent $\mathrm{K}^{+}\left(\mathrm{K}_{\text {ATP }}\right)$ channel opener, minoxidil, a potent arterial vasodilator which has long been used to treat hypertension. Minoxidil-induced $\mathrm{K}^{+}$efflux leads to enhancement of elastin synthesis in cultured VSMCs and skin fibroblasts [151,154]. In vivo studies have also demonstrated that the elastin content and/or thickness of elastic lamellae are increased by minoxidil treatment in several animal models: Spontaneously Hypertensive Rats (SHR) [155], Brown Norway (BN) rats [156], old C57B1/6J mice [157] and Eln+/- mice [158]. Chronic treatment of mice with minoxidil also results in improvements of the arterial mechanics and cerebral perfusion and, at least in aged animals, in neosynthesis of elastic fibers and protection of pre-existing elastic fibers [157-159]. Other $\mathrm{K}_{\mathrm{ATP}}$ channel openers, like diazoxide or nicorandil, exert an effect on in vivo elastin synthesis similar to those induced by minoxidil $[156,160]$, while pinacidil and some cromakalim or diazoxide derivatives have also been shown to induce elastin production by cultured VSMCs in rats $[156,161,162]$. However, treatment of animals with other antihypertensive drugs, either angiotensin-II type 1 receptor blocker, beta blocker or calcium channel blocker, does not modify the elastin content in arteries [163].

Numerous cytokines which inhibit tropoelastin transcription act through the activation of the Ras/MEK/ERK signalling pathway [150]. The increase in $\left[\mathrm{Ca}^{2+}\right]_{\mathrm{i}}$ in VSMCs also stimulates ERK1/2 phosphorylation. The inhibition of this signalling pathway could thus be a strategy to increase the elastin content in arteries. Actually, by performing in vitro and in vivo experiments in rats, it has been demonstrated that inhibition of the ERK1/2 phosphorylation leads to increases in elastin synthesis by VSMCs and elastin content in the aorta [153]. The importance of this pathway in elastin metabolism has been confirmed by the demonstration that cortistatin reduces elastin degradation, MMP-2 and -9 expressions and aneurysm progression through the inhibition of the ERK1/2 signaling pathways [164]. 
Of importance, it has also previously been shown that ERK1/2 signaling is involved in elastin peptide signaling through the elastin receptor complex (ERC) [94].

The general impact of the pharmacological treatments modulating the $\mathrm{K}_{\mathrm{ATP}}$ channels-Ca ${ }^{2+}$ channelsERK1/2 pathways described above is illustrated in Figure 1.

MEK inhibitors have also been used in order to stimulate elastin synthesis by cells isolated from patients with Costello syndrome, a developmental disorder characterized by hyper-activation of the mitogenic Ras-Raf-MEK/ERK pathway and inhibition of elastogenesis. The treatment of dermal fibroblasts derived from these patients with the MEK inhibitor PD98059 leads to the concomitant inhibition of cell proliferation and recovery of elastin production [165].

Completely different therapeutic strategies have also been tested to stimulate elastin synthesis using in vitro or in vivo models. Cenizo and colleagues have used a dill extract to induce LOXL gene expression in dermal fibroblasts, resulting in elastin content increase in dermal and skin equivalents as well as skin elasticity elevation in vivo in humans [166,167].

In addition, based on a previous work which has shown that microRNA (miR)-29 mimics downregulate the expression of elastin (ELN) as well as parts of collagen type I (COL1A1) and collagen type III (COL3A1) genes, the team of William C. Sessa has demonstrated that inhibition of miR-29a can increase ELN expression in human cells (skin fibroblasts, VSMCs, bioengineered vessels) and in cells from patients with ELN haploinsufficiencies (supravalvular aortic stenosis or Williams-Beuren syndrome). Using the same in vitro models, it was also demonstrated that engineered zinc-finger protein transcription factors that target the ELN gene can also be used to stimulate the expression of elastin $[168,169]$. However, these potential therapeutic molecules have not been tested in vivo yet and need additional investigations for validation of their therapeutic potential.

\section{CONCLUSION}


Elastic fibers represent a major innovation in the course of the evolution of species. Their mechanical properties of resilience and elasticity under relatively high strain-stress, together with the protective action of collagen fibers, have permitted the emergence of large arteries adapted for the efficient but demanding close circulation of vertebrates. During development, the progressive expression and assembly of the elastic fiber components adapt the structure-function of the arteries to the changing mechanical requirements imposed by the constitution of the complex cardiovascular system. The stopping of the production of the main constituent of elastic fibers, elastin, during childhood, therefore preventing further assembly of elastic fibers, results in the presence of a limited and non-reconstitutable stock of elastic fibers at the end of growth. During adulthood, the activity of proteolytic enzymes progressively degrades the existing elastic fibers and the arterial function, progressively leading to the deleterious elevated blood pressure, increased pulse pressure and altered hemodynamics observed during aging (Figure 2). The impossibility to physiologically replace the degraded elastic fibers, i.e. repair the arterial wall and re-establish a normal function of elastic arteries, questions the reasons for the limitation in time of the elastic fiber production. Is it a simple illustration disposable soma theory of aging, postulating that our bodies are important only until transmission of the genes to the next generation, then become unimportant? The answer is possibly more complex and could rely on the fact that elastic fibers are assembled during development and, later on, are extended by the growth of the organs, which could be necessary for reaching their mature mechanical properties [31]. A production of arterial elastic fibers after the end of growth could result in permanently unextended fibers which would not present normal elastic properties, then would not be completely efficient for endowing the large arteries with the needed mechanical properties. This hypothesis is supported by the fact that pharmacological reinduction of the expression of elastin and enzymes required for elastic fiber assembly, in the aorta of aged animals, results in the neosynthesis of elastic fibers that are not all normally arranged and oriented (figure 2). This has contrasted functional consequences: the important return of the aorta stress-strain relation closer to that of young adults, although with no significant 
impact on aorta distensibility and, surprisingly, a slight increase in aorta stiffness [157]. The search for new conditions allowing for elastic fiber arrangement and function optimization after elastin synthesis reinduction could be a future challenge in order to substantially improve the elasticity of large arteries in aged animals.

\section{ACKNOWLEDGMENTS}

The authors thank Dr. Ladislas Robert for his advices and decisive findings that he made in the field. Thanks also to the Association Autour des Williams (France), the Region Rhône-Alpes (France), the European Commission (grants TELASTAR, 5th PCRD, No. QLK6-CT-2001-00332 and ELAST-AGE, $6^{\text {th }}$ PCRD, No. LSHM-CT-2005-018960) and the Agence Nationale de la Recherche (ANR, France, grant Arterylastic: ANR-18-CE18-0001) for fundings.

\section{REFERENCES}

[1] T.A. Cook, N.A. Salmo, P.O. Yates, The elasticity of the internal lamina, J. Pathol. 117 (1975) 253-258. doi:10.1002/path.1711170408.

[2] M.R. Roach, A.C. Burton, The reason for the shape of the distensibility curves of arteries, Can. J. Biochem. Physiol. 35 (1957) 681-690.

[3] H. Wolinsky, S. Glagov, STRUCTURAL BASIS FOR THE STATIC MECHANICAL PROPERTIES OF THE AORTIC MEDIA, Circ. Res. 14 (1964) 400-413.

[4] W.D. Tucker, K. Mahajan, Anatomy, Blood Vessels, in: StatPearls, StatPearls Publishing, Treasure Island (FL), 2019. http://www.ncbi.nlm.nih.gov/books/NBK470401/ (accessed April 25, 2019).

[5] M.P. Jacob, Extracellular matrix remodeling and matrix metalloproteinases in the vascular wall during aging and in pathological conditions, Biomed. Pharmacother. Biomedecine Pharmacother. 57 (2003) 195-202.

[6] C.M. Kelleher, S.E. McLean, R.P. Mecham, Vascular extracellular matrix and aortic development, Curr. Top. Dev. Biol. 62 (2004) 153-188. doi:10.1016/S00702153(04)62006-0.

[7] A.K. Baldwin, A. Simpson, R. Steer, S.A. Cain, C.M. Kielty, Elastic fibres in health and disease, Expert Rev. Mol. Med. 15 (2013) e8. doi:10.1017/erm.2013.9.

[8] L. Debelle, A.M. Tamburro, Elastin: molecular description and function, Int. J. Biochem. Cell Biol. 31 (1999) 261-272. 
[9] M.A. Lillie, G.J. David, J.M. Gosline, Mechanical role of elastin-associated microfibrils in pig aortic elastic tissue, Connect. Tissue Res. 37 (1998) 121-141.

[10] H. Yanagisawa, J. Wagenseil, Elastic fibers and biomechanics of the aorta: Insights from mouse studies, Matrix Biol. J. Int. Soc. Matrix Biol. (2019). doi:10.1016/j.matbio.2019.03.001.

[11] G. Faury, Function-structure relationship of elastic arteries in evolution: from microfibrils to elastin and elastic fibres, Pathol. Biol. (Paris). 49 (2001) 310-325.

[12] J.E. Wagenseil, R.P. Mecham, Vascular extracellular matrix and arterial mechanics, Physiol. Rev. 89 (2009) 957-989. doi:10.1152/physrev.00041.2008.

[13] S. Laurent, J. Cockcroft, L. Van Bortel, P. Boutouyrie, C. Giannattasio, D. Hayoz, B. Pannier, C. Vlachopoulos, I. Wilkinson, H. Struijker-Boudier, European Network for Noninvasive Investigation of Large Arteries, Expert consensus document on arterial stiffness: methodological issues and clinical applications, Eur. Heart J. 27 (2006) 2588-2605. doi:10.1093/eurheartj/ehl254.

[14] H. Wolinsky, S. Glagov, A lamellar unit of aortic medial structure and function in mammals, Circ. Res. 20 (1967) 99-111.

[15] D.M. Basalyga, D.T. Simionescu, W. Xiong, B.T. Baxter, B.C. Starcher, N.R. Vyavahare, Elastin degradation and calcification in an abdominal aorta injury model: role of matrix metalloproteinases, $\quad$ Circulation. $\quad 110 \quad$ (2004) 3480-3487. doi:10.1161/01.CIR.0000148367.08413.E9.

[16] S.E. Greenwald, Ageing of the conduit arteries, J. Pathol. 211 (2007) 157-172. doi:10.1002/path.2101.

[17] S. Hodis, M. Zamir, Mechanical events within the arterial wall: The dynamic context for elastin fatigue, J. Biomech. 42 (2009) 1010-1016. doi:10.1016/j.jbiomech.2009.02.010.

[18] L. de R. Mikael, A.M.G. de Paiva, M.M. Gomes, A.L.L. Sousa, P.C.B.V. Jardim, P.V. de O. Vitorino, M.B. Euzébio, W. de M. Sousa, W.K.S. Barroso, Vascular Aging and Arterial Stiffness, Arq. Bras. Cardiol. 109 (2017) 253-258. doi:10.5935/abc.20170091.

[19] M. Janić, M. Lunder, M. Sabovič, Arterial stiffness and cardiovascular therapy, BioMed Res. Int. 2014 (2014) 621437. doi:10.1155/2014/621437.

[20] M. Cecelja, P. Chowienczyk, Role of arterial stiffness in cardiovascular disease, JRSM Cardiovasc. Dis. 1 (2012). doi:10.1258/cvd.2012.012016.

[21] H. Astrand, J. Stalhand, J. Karlsson, M. Karlsson, B. Sonesson, T. Länne, In vivo estimation of the contribution of elastin and collagen to the mechanical properties in the human abdominal aorta: effect of age and sex, J. Appl. Physiol. Bethesda Md 1985. 110 (2011) 176-187. doi:10.1152/japplphysiol.00579.2010.

[22] S. Bonapace, A. Rossi, M. Cicoira, G. Targher, F. Valbusa, A. Benetos, C. Vassanelli, Increased aortic pulse wave velocity as measured by echocardiography is strongly associated with poor prognosis in patients with heart failure, J. Am. Soc. Echocardiogr. Off. Publ. Am. Soc. Echocardiogr. 26 (2013) 714-720. doi:10.1016/j.echo.2013.03.022.

[23] M. Husmann, V. Jacomella, C. Thalhammer, B.R. Amann-Vesti, Markers of arterial stiffness in peripheral arterial disease, VASA Z. Gefasskrankheiten. 44 (2015) 341-348. doi:10.1024/0301-1526/a000452.

[24] M. Kozakova, C. Morizzo, D. Guarino, G. Federico, M. Miccoli, C. Giannattasio, C. Palombo, The impact of age and risk factors on carotid and carotid-femoral pulse wave velocity, J. Hypertens. 33 (2015) 1446-1451. doi:10.1097/HJH.0000000000000582.

[25] S. Novella, A.P. Dantas, G. Segarra, P. Medina, C. Hermenegildo, Vascular Aging in Women: is Estrogen the Fountain of Youth?, Front. Physiol. 3 (2012) 165. doi:10.3389/fphys.2012.00165.

[26] B. Jani, C. Rajkumar, Ageing and vascular ageing, Postgrad. Med. J. 82 (2006) 357-362. doi:10.1136/pgmj.2005.036053. 
[27] A.A. Ahimastos, M. Formosa, A.M. Dart, B.A. Kingwell, Gender differences in large artery stiffness pre- and post puberty, J. Clin. Endocrinol. Metab. 88 (2003) 5375-5380. doi:10.1210/jc.2003-030722.

[28] H.-Y. Lee, B.-H. Oh, Aging and arterial stiffness, Circ. J. Off. J. Jpn. Circ. Soc. 74 (2010) 2257-2262.

[29] R.B. Hickler, Aortic and large artery stiffness: current methodology and clinical correlations, Clin. Cardiol. 13 (1990) 317-322.

[30] T.K. Waddell, A.M. Dart, C.D. Gatzka, J.D. Cameron, B.A. Kingwell, Women exhibit a greater age-related increase in proximal aortic stiffness than men, J. Hypertens. 19 (2001) 2205-2212.

[31] J.D. Humphrey, E.R. Dufresne, M.A. Schwartz, Mechanotransduction and extracellular matrix homeostasis, Nat. Rev. Mol. Cell Biol. 15 (2014) 802-812. doi:10.1038/nrm3896.

[32] H. van Meurs-van Woezik, H.W. Klein, L. Markus-Silvis, P. Krediet, Comparison of the growth of the tunica media of the ascending aorta, aortic isthmus and descending aorta in infants and children, J. Anat. 136 (1983) 273-281.

[33] S. Basu, B.N. Datta, N. Khandelwal, Morphologic changes in pulmonary vasculature with arteriographic correlation, Angiology. $47 \quad$ (1996) 375-380. doi:10.1177/000331979604700408.

[34] A.J. Lilly, A. Mazan, D.A. Scott, G. Lacaud, V. Kouskoff, SOX7 expression is critically required in FLK1-expressing cells for vasculogenesis and angiogenesis during mouse embryonic development, Mech. Dev. 146 (2017) 31-41. doi:10.1016/j.mod.2017.05.004.

[35] Y. Oike, Y. Ito, K. Hamada, X.-Q. Zhang, K. Miyata, F. Arai, T. Inada, K. Araki, N. Nakagata, M. Takeya, Y.Y. Kisanuki, M. Yanagisawa, N.W. Gale, T. Suda, Regulation of vasculogenesis and angiogenesis by EphB/ephrin-B2 signaling between endothelial cells and surrounding mesenchymal cells, Blood. 100 (2002) 1326-1333.

[36] C.S. Craft, T.J. Broekelmann, R.P. Mecham, Microfibril-associated glycoproteins MAGP1 and MAGP-2 in disease, Matrix Biol. J. Int. Soc. Matrix Biol. 71-72 (2018) 100-111. doi:10.1016/j.matbio.2018.03.006.

[37] M. Sauvage, N. Hinglais, C. Mandet, C. Badier, F. Deslandes, J.B. Michel, M.P. Jacob, Localization of elastin mRNA and TGF-betal in rat aorta and caudal artery as a function of age, Cell Tissue Res. 291 (1998) 305-314.

[38] J.E. Wagenseil, R.P. Mecham, New insights into elastic fiber assembly, Birth Defects Res. Part C Embryo Today Rev. 81 (2007) 229-240. doi:10.1002/bdrc.20111.

[39] H. Nakamura, Electron microscopic study of the prenatal development of the thoracic aorta in the rat, Am. J. Anat. 181 (1988) 406-418. doi:10.1002/aja.1001810409.

[40] Y. Fukuda, V.J. Ferrans, R.G. Crystal, Development of elastic fibers of nuchal ligament, aorta, and lung of fetal and postnatal sheep: an ultrastructural and electron microscopic immunohistochemical study, Am. J. Anat. 170 (1984) 597-629. doi:10.1002/aja.1001700407.

[41] R.P. Mecham, Elastin in lung development and disease pathogenesis, Matrix Biol. J. Int. Soc. Matrix Biol. 73 (2018) 6-20. doi:10.1016/j.matbio.2018.01.005.

[42] D.Y. Li, B. Brooke, E.C. Davis, R.P. Mecham, L.K. Sorensen, B.B. Boak, E. Eichwald, M.T. Keating, Elastin is an essential determinant of arterial morphogenesis, Nature. 393 (1998) 276-280. doi:10.1038/30522.

[43] S.K. Karnik, B.S. Brooke, A. Bayes-Genis, L. Sorensen, J.D. Wythe, R.S. Schwartz, M.T. Keating, D.Y. Li, A critical role for elastin signaling in vascular morphogenesis and disease, Dev. Camb. Engl. 130 (2003) 411-423.

[44] S.K. Karnik, J.D. Wythe, L. Sorensen, B.S. Brooke, L.D. Urness, D.Y. Li, Elastin induces myofibrillogenesis via a specific domain, VGVAPG, Matrix Biol. J. Int. Soc. Matrix Biol. 22 (2003) 409-425. 
[45] M. Gabriela Espinosa, M. Catalin Staiculescu, J. Kim, E. Marin, J.E. Wagenseil, Elastic Fibers and Large Artery Mechanics in Animal Models of Development and Disease, J. Biomech. Eng. 140 (2018). doi:10.1115/1.4038704.

[46] S.M. Wells, B.L. Langille, S.L. Adamson, In vivo and in vitro mechanical properties of the sheep thoracic aorta in the perinatal period and adulthood, Am. J. Physiol. 274 (1998) H1749-1760. doi:10.1152/ajpheart.1998.274.5.H1749.

[47] S.M. Wells, B.L. Langille, J.M. Lee, S.L. Adamson, Determinants of mechanical properties in the developing ovine thoracic aorta, Am. J. Physiol. 277 (1999) H1385-1391. doi:10.1152/ajpheart.1999.277.4.H1385.

[48] C.L. Berry, T. Looker, J. Germain, Nucleic acid and scleroprotein content of the developing human aorta, J. Pathol. 108 (1972) 265-274. doi:10.1002/path.1711080402.

[49] S.E. Greenwald, C.L. Berry, S.G. Haworth, Changes in the distensibility of the intrapulmonary arteries in the normal newborn and growing pig, Cardiovasc. Res. 16 (1982) 716-725.

[50] P.M. Vanhoutte, H. Shimokawa, M. Feletou, E.H.C. Tang, Endothelial dysfunction and vascular disease - a 30th anniversary update, Acta Physiol. Oxf. Engl. 219 (2017) 22-96. doi:10.1111/apha.12646.

[51] H. Sugitani, H. Wachi, S. Tajima, Y. Seyama, Nitric oxide stimulates elastin expression in chick aortic smooth muscle cells, Biol. Pharm. Bull. 24 (2001) 461-464.

[52] H.Y. Qiu, B. Valtier, H.A. Struyker-Boudier, B.I. Levy, Mechanical and contractile properties of in situ localized mesenteric arteries in normotensive and spontaneously hypertensive rats, J. Pharmacol. Toxicol. Methods. 33 (1995) 159-170.

[53] F.L. Wuyts, V.J. Vanhuyse, G.J. Langewouters, W.F. Decraemer, E.R. Raman, S. Buyle, Elastic properties of human aortas in relation to age and atherosclerosis: a structural model, Phys. Med. Biol. 40 (1995) 1577-1597.

[54] P.B. Dobrin, A.A. Rovick, Influence of vascular smooth muscle on contractile mechanics and elasticity of arteries, Am. J. Physiol. 217 (1969) 1644-1651. doi:10.1152/ajplegacy.1969.217.6.1644.

[55] G. Faury, G.M. Maher, D.Y. Li, M.T. Keating, R.P. Mecham, W.A. Boyle, Relation between outer and luminal diameter in cannulated arteries, Am. J. Physiol. 277 (1999) H1745-1753. doi:10.1152/ajpheart.1999.277.5.H1745.

[56] J.M. Davidson, O. Zoia, J.M. Liu, Modulation of transforming growth factor-beta 1 stimulated elastin and collagen production and proliferation in porcine vascular smooth muscle cells and skin fibroblasts by basic fibroblast growth factor, transforming growth factor-alpha, and insulin-like growth factor-I, J. Cell. Physiol. 155 (1993) 149-156. doi:10.1002/jcp.1041550119.

[57] T.E. Clark, M.A. Lillie, A.W. Vogl, J.M. Gosline, R.E. Shadwick, Mechanical contribution of lamellar and interlamellar elastin along the mouse aorta, J. Biomech. 48 (2015) 35993605. doi:10.1016/j.jbiomech.2015.08.004.

[58] B.B. Aaron, J.M. Gosline, Elastin as a random-network elastomer: A mechanical and optical analysis of single elastin fibers, Biopolymers. 20 (1981) 1247-1260. doi:10.1002/bip.1981.360200611.

[59] M.-J. Chow, R. Turcotte, C.P. Lin, Y. Zhang, Arterial extracellular matrix: a mechanobiological study of the contributions and interactions of elastin and collagen, Biophys. J. 106 (2014) 2684-2692. doi:10.1016/j.bpj.2014.05.014.

[60] J. Rosenbloom, W.R. Abrams, R. Mecham, Extracellular matrix 4: the elastic fiber, FASEB J. Off. Publ. Fed. Am. Soc. Exp. Biol. 7 (1993) 1208-1218.

[61] M.A. Awal, M. Matsumoto, H. Nishinakagawa, Morphometrical changes of the arterial walls of main arteries from heart to the abdomino-inguinal mammary glands of rat from virgin through pregnancy, lactation and post-weaning, J. Vet. Med. Sci. 57 (1995) 251-256. 
[62] O. Fritze, B. Romero, M. Schleicher, M.P. Jacob, D.-Y. Oh, B. Starcher, K. SchenkeLayland, J. Bujan, U.A. Stock, Age-related changes in the elastic tissue of the human aorta, J. Vasc. Res. 49 (2012) 77-86. doi:10.1159/000331278.

[63] T. Fülöp, S.M. Wei, L. Robert, M.P. Jacob, Determination of elastin peptides in normal and arteriosclerotic human sera by ELISA, Clin. Physiol. Biochem. 8 (1990) 273-282.

[64] G. Faury, Role of the elastin-laminin receptor in the cardiovascular system, Pathol. Biol. (Paris). 46 (1998) 517-526.

[65] G. Faury, Y. Usson, M. Robert-Nicoud, L. Robert, J. Verdetti, Nuclear and cytoplasmic free calcium level changes induced by elastin peptides in human endothelial cells, Proc. Natl. Acad. Sci. U. S. A. 95 (1998) 2967-2972.

[66] A. Ostuni, M.D. Lograno, A.R. Gasbarro, F. Bisaccia, A.M. Tamburro, Novel properties of peptides derived from the sequence coded by exon 26A of human elastin, Int. J. Biochem. Cell Biol. 34 (2002) 130-135.

[67] M.D. Lograno, F. Bisaccia, A. Ostuni, E. Daniele, A.M. Tamburro, Identification of elastin peptides with vasorelaxant activity on rat thoracic aorta, Int. J. Biochem. Cell Biol. 30 (1998) 497-503.

[68] G. Faury, M.T. Ristori, J. Verdetti, M.P. Jacob, L. Robert, Effect of elastin peptides on vascular tone, J. Vasc. Res. 32 (1995) 112-119. doi:10.1159/000159084.

[69] M.E. Curran, D.L. Atkinson, A.K. Ewart, C.A. Morris, M.F. Leppert, M.T. Keating, The elastin gene is disrupted by a translocation associated with supravalvular aortic stenosis, Cell. 73 (1993) 159-168.

[70] A.K. Ewart, C.A. Morris, D. Atkinson, W. Jin, K. Sternes, P. Spallone, A.D. Stock, M. Leppert, M.T. Keating, Hemizygosity at the elastin locus in a developmental disorder, Williams syndrome, Nat. Genet. 5 (1993) 11-16. doi:10.1038/ng0993-11.

[71] G. Faury, M. Pezet, R.H. Knutsen, W.A. Boyle, S.P. Heximer, S.E. McLean, R.K. Minkes, K.J. Blumer, A. Kovacs, D.P. Kelly, D.Y. Li, B. Starcher, R.P. Mecham, Developmental adaptation of the mouse cardiovascular system to elastin haploinsufficiency, J. Clin. Invest. 112 (2003) 1419-1428. doi:10.1172/JCI19028.

[72] M.L. Duque Lasio, B.A. Kozel, Elastin-driven genetic diseases, Matrix Biol. J. Int. Soc. Matrix Biol. 71-72 (2018) 144-160. doi:10.1016/j.matbio.2018.02.021.

[73] H.C. Dietz, G.R. Cutting, R.E. Pyeritz, C.L. Maslen, L.Y. Sakai, G.M. Corson, E.G. Puffenberger, A. Hamosh, E.J. Nanthakumar, S.M. Curristin, Marfan syndrome caused by a recurrent de novo missense mutation in the fibrillin gene, Nature. 352 (1991) 337-339. doi:10.1038/352337a0.

[74] F. Ramirez, C. Caescu, E. Wondimu, J. Galatioto, Marfan syndrome; A connective tissue disease at the crossroads of mechanotransduction, TGF $\beta$ signaling and cell stemness, Matrix Biol. J. Int. Soc. Matrix Biol. 71-72 (2018) 82-89. doi:10.1016/j.matbio.2017.07.004.

[75] G.F. Mitchell, Effects of central arterial aging on the structure and function of the peripheral vasculature: implications for end-organ damage, J. Appl. Physiol. Bethesda Md 1985. 105 (2008) 1652-1660. doi:10.1152/japplphysiol.90549.2008.

[76] M.F. O'Rourke, J. Hashimoto, Mechanical factors in arterial aging: a clinical perspective, J. Am. Coll. Cardiol. 50 (2007) 1-13. doi:10.1016/j.jacc.2006.12.050.

[77] M.J. Sherratt, Tissue elasticity and the ageing elastic fibre, Age. 31 (2009) 305-325. doi:10.1007/s11357-009-9103-6.

[78] J. Labat-Robert, M. Bihari-Varga, L. Robert, Extracellular matrix, FEBS Lett. 268 (1990) 386-393.

[79] M.A. Lillie, G.W. Chalmers, J.M. Gosline, The effects of heating on the mechanical properties of arterial elastin, Connect. Tissue Res. 31 (1994) 23-35.

[80] N. Thorin-Trescases, E. Thorin, Lifelong Cyclic Mechanical Strain Promotes Large Elastic 
Artery Stiffening: Increased Pulse Pressure and Old Age-Related Organ Failure, Can. J. Cardiol. 32 (2016) 624-633. doi:10.1016/j.cjca.2015.12.022.

[81] C. Palombo, M. Kozakova, Arterial stiffness, atherosclerosis and cardiovascular risk: Pathophysiologic mechanisms and emerging clinical indications, Vascul. Pharmacol. 77 (2016) 1-7. doi:10.1016/j.vph.2015.11.083.

[82] M.E. Safar, Arterial aging-hemodynamic changes and therapeutic options, Nat. Rev. Cardiol. 7 (2010) 442-449. doi:10.1038/nrcardio.2010.96.

[83] D.R. Sell, V.M. Monnier, Molecular basis of arterial stiffening: role of glycation - a minireview, Gerontology. 58 (2012) 227-237. doi:10.1159/000334668.

[84] G.L. Bakris, A.J. Bank, D.A. Kass, J.M. Neutel, R.A. Preston, S. Oparil, Advanced glycation end-product cross-link breakers. A novel approach to cardiovascular pathologies related to the aging process, Am. J. Hypertens. 17 (2004) 23S-30S. doi:10.1016/j.amjhyper.2004.08.022.

[85] M. Kosmopoulos, D. Drekolias, P.D. Zavras, C. Piperi, A.G. Papavassiliou, Impact of advanced glycation end products (AGEs) signaling in coronary artery disease, Biochim. Biophys. Acta BBA - Mol. Basis Dis. 1865 (2019) 611-619. doi:10.1016/j.bbadis.2019.01.006.

[86] C. Cantini, P. Kieffer, B. Corman, P. Limiñana, J. Atkinson, I. Lartaud-Idjouadiene, Aminoguanidine and aortic wall mechanics, structure, and composition in aged rats, Hypertens. Dallas Tex 1979. 38 (2001) 943-948.

[87] S. Peng, J. Glennert, P. Westermark, Medin-amyloid: a recently characterized ageassociated arterial amyloid form affects mainly arteries in the upper part of the body, Amyloid Int. J. Exp. Clin. Investig. Off. J. Int. Soc. Amyloidosis. 12 (2005) 96-102. doi:10.1080/13506120500107006.

[88] L. Robert, A.M. Robert, T. Fülöp, Rapid increase in human life expectancy: will it soon be limited by the aging of elastin?, Biogerontology. 9 (2008) 119-133. doi:10.1007/s10522007-9122-6.

[89] S. Chakraborti, M. Mandal, S. Das, A. Mandal, T. Chakraborti, Regulation of matrix metalloproteinases: an overview, Mol. Cell. Biochem. 253 (2003) 269-285.

[90] E. Allaire, B. Muscatelli-Groux, C. Mandet, A.-M. Guinault, P. Bruneval, P. Desgranges, A. Clowes, D. Méllière, J.-P. Becquemin, Paracrine effect of vascular smooth muscle cells in the prevention of aortic aneurysm formation, J. Vasc. Surg. 36 (2002) 1018-1026.

[91] M.A. Cattell, J.C. Anderson, P.S. Hasleton, Age-related changes in amounts and concentrations of collagen and elastin in normotensive human thoracic aorta, Clin. Chim. Acta Int. J. Clin. Chem. 245 (1996) 73-84.

[92] H. Taghizadeh, M. Tafazzoli-Shadpour, Characterization of mechanical properties of lamellar structure of the aortic wall: Effect of aging, J. Mech. Behav. Biomed. Mater. 65 (2017) 20-28. doi:10.1016/j.jmbbm.2016.08.011.

[93] A. Schmidt-Trucksäss, D. Grathwohl, A. Schmid, R. Boragk, C. Upmeier, J. Keul, M. Huonker, Structural, functional, and hemodynamic changes of the common carotid artery with age in male subjects, Arterioscler. Thromb. Vasc. Biol. 19 (1999) 1091-1097.

[94] A. Wahart, T. Hocine, C. Albrecht, A. Henry, T. Sarazin, L. Martiny, H. El Btaouri, P. Maurice, A. Bennasroune, B. Romier-Crouzet, S. Blaise, L. Duca, Role of elastin peptides and elastin receptor complex in metabolic and cardiovascular diseases, FEBS J. (2019). doi:10.1111/febs. 14836.

[95] G. Faury, S. Garnier, A.S. Weiss, J. Wallach, T. Fülöp, M.P. Jacob, R.P. Mecham, L. Robert, J. Verdetti, Action of tropoelastin and synthetic elastin sequences on vascular tone and on free $\mathrm{Ca} 2+$ level in human vascular endothelial cells, Circ. Res. 82 (1998) 328-336.

[96] Z. Varga, M.P. Jacob, L. Robert, J. Csongor, T. Fulop, Age-dependent changes of K-elastin stimulated effector functions of human phagocytic cells: relevance for atherogenesis, Exp. 
Gerontol. 32 (1997) 653-662.

[97] T. Fulöp, N. Douziech, M.P. Jacob, M. Hauck, J. Wallach, L. Robert, Age-related alterations in the signal transduction pathways of the elastin-laminin receptor, Pathol. Biol. (Paris). 49 (2001) 339-348.

[98] G. Faury, A. Chabaud, M.T. Ristori, L. Robert, J. Verdetti, Effect of age on the vasodilatory action of elastin peptides, Mech. Ageing Dev. 95 (1997) 31-42.

[99] G. Faury, L. Robert, J. Verdetti, The age-dependent vasodilatation and endothelial calcium influx induced by elastin peptides are modulated by extracellular glucose level, Biomed. Pharmacother. 57 (2003) 216-222. doi:10.1016/S0753-3322(03)00053-2.

[100] L. Robert, Aging of the vascular wall and atherogenesis: role of the elastin-laminin receptor, Atherosclerosis. 123 (1996) 169-179.

[101] J. Ferruzzi, M.R. Bersi, R.P. Mecham, F. Ramirez, H. Yanagisawa, G. Tellides, J.D. Humphrey, Loss of Elastic Fiber Integrity Compromises Common Carotid Artery Function: Implications for Vascular Aging, Artery Res. 14 (2016) 41-52. doi:10.1016/j.artres.2016.04.001.

[102] B. Mariko, M. Pezet, B. Escoubet, S. Bouillot, J.-P. Andrieu, B. Starcher, D. Quaglino, M.-P. Jacob, P. Huber, F. Ramirez, G. Faury, Fibrillin-1 genetic deficiency leads to pathological ageing of arteries in mice, J. Pathol. 224 (2011) 33-44. doi:10.1002/path.2840.

[103] M. Pezet, M.-P. Jacob, B. Escoubet, D. Gheduzzi, E. Tillet, P. Perret, P. Huber, D. Quaglino, R. Vranckx, D.Y. Li, B. Starcher, W.A. Boyle, R.P. Mecham, G. Faury, Elastin haploinsufficiency induces alternative aging processes in the aorta, Rejuvenation Res. 11 (2008) 97-112. doi:10.1089/rej.2007.0587.

[104] A. Doyon, D. Kracht, A.K. Bayazit, M. Deveci, A. Duzova, R.T. Krmar, M. Litwin, A. Niemirska, B. Oguz, B.M.W. Schmidt, B. Sözeri, U. Querfeld, A. Melk, F. Schaefer, E. Wühl, 4C Study Consortium, Carotid artery intima-media thickness and distensibility in children and adolescents: reference values and role of body dimensions, Hypertens. Dallas Tex 1979. 62 (2013) 550-556. doi:10.1161/HYPERTENSIONAHA.113.01297.

[105] D.H.J. Thijssen, S.E. Carter, D.J. Green, Arterial structure and function in vascular ageing: are you as old as your arteries?, J. Physiol. 594 (2016) 2275-2284. doi:10.1113/JP270597.

[106] P.M. Nilsson, P. Boutouyrie, P. Cunha, V. Kotsis, K. Narkiewicz, G. Parati, E. Rietzschel, A. Scuteri, S. Laurent, Early vascular ageing in translation: from laboratory investigations to clinical applications in cardiovascular prevention, J. Hypertens. 31 (2013) 1517-1526. doi:10.1097/HJH.0b013e328361e4bd.

[107] A.H. Davies, The Seriousness of Chronic Venous Disease: A Review of Real-World Evidence, Adv. Ther. 36 (2019) 5-12. doi:10.1007/s12325-019-0881-7.

[108] J.A. Elefteriades, E.A. Farkas, Thoracic aortic aneurysm clinically pertinent controversies and uncertainties, J. Am. Coll. Cardiol. 55 (2010) 841-857. doi:10.1016/j.jacc.2009.08.084.

[109] E. Altobelli, L. Rapacchietta, V.F. Profeta, R. Fagnano, Risk Factors for Abdominal Aortic Aneurysm in Population-Based Studies: A Systematic Review and Meta-Analysis, Int. J. Environ. Res. Public. Health. 15 (2018). doi:10.3390/ijerph15122805.

[110] H. Abdulameer, H. Al Taii, S.G. Al-Kindi, R. Milner, Epidemiology of fatal ruptured aortic aneurysms in the United States (1999-2016), J. Vasc. Surg. 69 (2019) 378-384.e2. doi:10.1016/j.jvs.2018.03.435.

[111] S. Barquera, A. Pedroza-Tobías, C. Medina, L. Hernández-Barrera, K. Bibbins-Domingo, R. Lozano, A.E. Moran, Global Overview of the Epidemiology of Atherosclerotic Cardiovascular Disease, Arch. Med. Res. 46 (2015) 328-338. doi:10.1016/j.arcmed.2015.06.006.

[112] E.G. Lakatta, D. Levy, Arterial and cardiac aging: major shareholders in cardiovascular 
disease enterprises: Part I: aging arteries: a "set up" for vascular disease, Circulation. 107 (2003) 139-146. doi:10.1161/01.cir.0000048892.83521.58.

[113] G.K. Hansson, Inflammation, atherosclerosis, and coronary artery disease, N. Engl. J. Med. 352 (2005) 1685-1695. doi:10.1056/NEJMra043430.

[114] P. Lévy, M. Kohler, W.T. McNicholas, F. Barbé, R.D. McEvoy, V.K. Somers, L. Lavie, J.-L. Pépin, Obstructive sleep apnoea syndrome, Nat. Rev. Dis. Primer. 1 (2015) 15015. doi:10.1038/nrdp.2015.15.

[115] C. Arnaud, P.C. Beguin, S. Lantuejoul, J.-L. Pepin, C. Guillermet, G. Pelli, F. Burger, V. Buatois, C. Ribuot, J.-P. Baguet, F. Mach, P. Levy, M. Dematteis, The inflammatory preatherosclerotic remodeling induced by intermittent hypoxia is attenuated by RANTES/CCL5 inhibition, Am. J. Respir. Crit. Care Med. 184 (2011) 724-731. doi:10.1164/rccm.201012-2033OC.

[116] S. Iurciuc, A.M. Cimpean, F. Mitu, R. Heredea, M. Iurciuc, Vascular aging and subclinical atherosclerosis: why such a "never ending" and challenging story in cardiology?, Clin. Interv. Aging. 12 (2017) 1339-1345. doi:10.2147/CIA.S141265.

[117] M. Wang, R.E. Monticone, K.R. McGraw, Proinflammatory Arterial Stiffness Syndrome: A Signature of Large Arterial Aging, J. Vasc. Res. 55 (2018) 210-223. doi:10.1159/000490244.

[118] L. Rodríguez-Mañas, M. El-Assar, S. Vallejo, P. López-Dóriga, J. Solís, R. Petidier, M. Montes, J. Nevado, M. Castro, C. Gómez-Guerrero, C. Peiró, C.F. Sánchez-Ferrer, Endothelial dysfunction in aged humans is related with oxidative stress and vascular inflammation, Aging Cell. 8 (2009) 226-238. doi:10.1111/j.1474-9726.2009.00466.x.

[119] G.K. Sukhova, G.P. Shi, D.I. Simon, H.A. Chapman, P. Libby, Expression of the elastolytic cathepsins $\mathrm{S}$ and $\mathrm{K}$ in human atheroma and regulation of their production in smooth muscle cells, J. Clin. Invest. 102 (1998) 576-583. doi:10.1172/JCI181.

[120] J. Huynh, N. Nishimura, K. Rana, J.M. Peloquin, J.P. Califano, C.R. Montague, M.R. King, C.B. Schaffer, C.A. Reinhart-King, Age-related intimal stiffening enhances endothelial permeability and leukocyte transmigration, Sci. Transl. Med. 3 (2011) 112ra122. doi:10.1126/scitranslmed.3002761.

[121] L. González-Santiago, S. López-Ongil, M. Rodríguez-Puyol, D. Rodríguez-Puyol, Decreased nitric oxide synthesis in human endothelial cells cultured on type I collagen, Circ. Res. 90 (2002) 539-545. doi:10.1161/01.res.0000012445.68979.9d.

[122] A.W. Orr, M.Y. Lee, J.A. Lemmon, A. Yurdagul, M.F. Gomez, P.D.S. Bortz, B.R. Wamhoff, Molecular mechanisms of collagen isotype-specific modulation of smooth muscle cell phenotype, Arterioscler. Thromb. Vasc. Biol. 29 (2009) 225-231. doi:10.1161/ATVBAHA.108.178749.

[123] T. Fulop, A. Larbi, A. Fortun, L. Robert, A. Khalil, Elastin peptides induced oxidation of LDL by phagocytic cells, Pathol. Biol. (Paris). 53 (2005) 416-423. doi:10.1016/j.patbio.2004.12.023.

[124] P. Maurice, S. Blaise, S. Gayral, L. Debelle, M. Laffargue, W. Hornebeck, L. Duca, Elastin fragmentation and atherosclerosis progression: the elastokine concept, Trends Cardiovasc. Med. 23 (2013) 211-221. doi:10.1016/j.tcm.2012.12.004.

[125] A. Phinikaridou, S. Lacerda, B. Lavin, M.E. Andia, A. Smith, P. Saha, R.M. Botnar, Tropoelastin: A novel marker for plaque progression and instability, Circ. Cardiovasc. Imaging. 11 (2018). doi:10.1161/CIRCIMAGING.117.007303.

[126] D.A. Chistiakov, A.N. Orekhov, Y.V. Bobryshev, Vascular smooth muscle cell in atherosclerosis, Acta Physiol. Oxf. Engl. 214 (2015) 33-50. doi:10.1111/apha.12466.

[127] A.J. Cocciolone, J.Z. Hawes, M.C. Staiculescu, E.O. Johnson, M. Murshed, J.E. Wagenseil, Elastin, arterial mechanics, and cardiovascular disease, Am. J. Physiol. Heart Circ. Physiol. 315 (2018) H189-H205. doi:10.1152/ajpheart.00087.2018. 
[128] M. Wang, L. Jiang, R.E. Monticone, E.G. Lakatta, Proinflammation: the key to arterial aging, Trends Endocrinol. Metab. TEM. 25 (2014) 72-79. doi:10.1016/j.tem.2013.10.002.

[129] M. Wang, E.G. Lakatta, Altered regulation of matrix metalloproteinase-2 in aortic remodeling during aging, Hypertens. Dallas Tex 1979. 39 (2002) 865-873. doi:10.1161/01.hyp.0000014506.13322.66.

[130] K.W. Johnston, R.B. Rutherford, M.D. Tilson, D.M. Shah, L. Hollier, J.C. Stanley, Suggested standards for reporting on arterial aneurysms. Subcommittee on Reporting Standards for Arterial Aneurysms, Ad Hoc Committee on Reporting Standards, Society for Vascular Surgery and North American Chapter, International Society for Cardiovascular Surgery, J. Vasc. Surg. 13 (1991) 452-458.

[131] E.L. Verhoeven, M.R. Kapma, H. Groen, I.F. Tielliu, C.J. Zeebregts, F. Bekkema, J.J. van den Dungen, Mortality of ruptured abdominal aortic aneurysm treated with open or endovascular repair, J. Vasc. Surg. 48 (2008) 1396-1400. doi:10.1016/j.jvs.2008.07.054.

[132] N. Sakalihasan, J.-B. Michel, A. Katsargyris, H. Kuivaniemi, J.-O. Defraigne, A. Nchimi, J.T. Powell, K. Yoshimura, R. Hultgren, Abdominal aortic aneurysms, Nat. Rev. Dis. Primer. 4 (2018) 34. doi:10.1038/s41572-018-0030-7.

[133] J.-B. Michel, G. Jondeau, D.M. Milewicz, From genetics to response to injury: vascular smooth muscle cells in aneurysms and dissections of the ascending aorta, Cardiovasc. Res. 114 (2018) 578-589. doi:10.1093/cvr/cvy006.

[134] A. Malashicheva, D. Kostina, A. Kostina, O. Irtyuga, I. Voronkina, L. Smagina, E. Ignatieva, N. Gavriliuk, V. Uspensky, O. Moiseeva, J. Vaage, A. Kostareva, Phenotypic and Functional Changes of Endothelial and Smooth Muscle Cells in Thoracic Aortic Aneurysms, Int. J. Vasc. Med. 2016 (2016) 3107879. doi:10.1155/2016/3107879.

[135] S.W. Rabkin, The Role Matrix Metalloproteinases in the Production of Aortic Aneurysm, Prog. Mol. Biol. Transl. Sci. 147 (2017) 239-265. doi:10.1016/bs.pmbts.2017.02.002.

[136] G. Ailawadi, J.L. Eliason, G.R. Upchurch, Current concepts in the pathogenesis of abdominal aortic aneurysm, J. Vasc. Surg. 38 (2003) 584-588.

[137] U. Raaz, A.M. Zöllner, I.N. Schellinger, R. Toh, F. Nakagami, M. Brandt, F.C. Emrich, Y. Kayama, S. Eken, M. Adam, L. Maegdefessel, T. Hertel, A. Deng, A. Jagger, M. Buerke, R.L. Dalman, J.M. Spin, E. Kuhl, P.S. Tsao, Segmental aortic stiffening contributes to experimental abdominal aortic aneurysm development, Circulation. 131 (2015) 1783-1795. doi:10.1161/CIRCULATIONAHA.114.012377.

[138] S.A. Gharib, A.M. Manicone, W.C. Parks, Matrix metalloproteinases in emphysema, Matrix Biol. J. Int. Soc. Matrix Biol. 73 (2018) 34-51. doi:10.1016/j.matbio.2018.01.018.

[139] A. Ferrara, S. Morganti, P. Totaro, A. Mazzola, F. Auricchio, Human dilated ascending aorta: Mechanical characterization via uniaxial tensile tests, J. Mech. Behav. Biomed. Mater. 53 (2016) 257-271. doi:10.1016/j.jmbbm.2015.08.021.

[140] C.J. Goergen, J. Azuma, K.N. Barr, L. Magdefessel, D.Y. Kallop, A. Gogineni, A. Grewall, R.M. Weimer, A.J. Connolly, R.L. Dalman, C.A. Taylor, P.S. Tsao, J.M. Greve, Influences of aortic motion and curvature on vessel expansion in murine experimental aneurysms, Arterioscler. Thromb. Vasc. Biol. 31 (2011) 270-279. doi:10.1161/ATVBAHA.110.216481.

[141] A. Karimi, D.M. Milewicz, Structure of the Elastin-Contractile Units in the Thoracic Aorta and How Genes That Cause Thoracic Aortic Aneurysms and Dissections Disrupt This Structure, Can. J. Cardiol. 32 (2016) 26-34. doi:10.1016/j.cjca.2015.11.004.

[142] A. Tsamis, J.T. Krawiec, D.A. Vorp, Elastin and collagen fibre microstructure of the human aorta in ageing and disease: a review, J. R. Soc. Interface. 10 (2013) 20121004. doi:10.1098/rsif.2012.1004.

[143] D.C. Iliopoulos, E.P. Kritharis, A.T. Giagini, S.A. Papadodima, D.P. Sokolis, Ascending thoracic aortic aneurysms are associated with compositional remodeling and vessel 
stiffening but not weakening in age-matched subjects, J. Thorac. Cardiovasc. Surg. 137 (2009) 101-109. doi:10.1016/j.jtcvs.2008.07.023.

[144] L. Pereira, K. Andrikopoulos, J. Tian, S.Y. Lee, D.R. Keene, R. Ono, D.P. Reinhardt, L.Y. Sakai, N.J. Biery, T. Bunton, H.C. Dietz, F. Ramirez, Targetting of the gene encoding fibrillin-1 recapitulates the vascular aspect of Marfan syndrome, Nat. Genet. 17 (1997) 218 222. doi:10.1038/ng1097-218.

[145] D. Guo, E.S. Regalado, L. Gong, X. Duan, R.L.P. Santos-Cortez, P. Arnaud, Z. Ren, B. Cai, E.M. Hostetler, R. Moran, D. Liang, A. Estrera, H.J. Safi, University of Washington Center for Mendelian Genomics, S.M. Leal, M.J. Bamshad, J. Shendure, D.A. Nickerson, G. Jondeau, C. Boileau, D.M. Milewicz, LOX Mutations Predispose to Thoracic Aortic Aneurysms and Dissections, Circ. Res. 118 (2016) 928-934. doi:10.1161/CIRCRESAHA.115.307130.

[146] V.S. Lee, C.M. Halabi, E.P. Hoffman, N. Carmichael, I. Leshchiner, C.G. Lian, A.J. Bierhals, D. Vuzman, Brigham Genomic Medicine, R.P. Mecham, N.Y. Frank, N.O. Stitziel, Loss of function mutation in LOX causes thoracic aortic aneurysm and dissection in humans, Proc. Natl. Acad. Sci. U. S. A. 113 (2016) 8759-8764. doi:10.1073/pnas.1601442113.

[147] M.-J. Goumans, P. Ten Dijke, TGF- $\beta$ Signaling in Control of Cardiovascular Function, Cold Spring Harb. Perspect. Biol. 10 (2018). doi:10.1101/cshperspect.a022210.

[148] C.L. Papke, H. Yanagisawa, Fibulin-4 and fibulin-5 in elastogenesis and beyond: Insights from mouse and human studies, Matrix Biol. J. Int. Soc. Matrix Biol. 37 (2014) 142-149. doi:10.1016/j.matbio.2014.02.004.

[149] H. Wei, J.H. Hu, S.N. Angelov, K. Fox, J. Yan, R. Enstrom, A. Smith, D.A. Dichek, Aortopathy in a Mouse Model of Marfan Syndrome Is Not Mediated by Altered Transforming Growth Factor $\beta$ Signaling, J. Am. Heart Assoc. 6 (2017). doi:10.1161/JAHA.116.004968.

[150] E.P. Sproul, W.S. Argraves, A cytokine axis regulates elastin formation and degradation, Matrix Biol. J. Int. Soc. Matrix Biol. 32 (2013) 86-94. doi:10.1016/j.matbio.2012.11.004.

[151] A. Hayashi, T. Suzuki, H. Wachi, S. Tajima, T. Nishikawa, S. Murad, S.R. Pinnell, Minoxidil stimulates elastin expression in aortic smooth muscle cells, Arch. Biochem. Biophys. 315 (1994) 137-141. doi:10.1006/abbi.1994.1482.

[152] I. Tokimitsu, S. Tajima, Inhibition of elastin synthesis by high potassium salt is mediated by $\mathrm{Ca} 2+$ influx in cultured smooth muscle cells in vitro: reciprocal effects of $\mathrm{K}+$ on elastin and collagen synthesis, J. Biochem. (Tokyo). 115 (1994) 536-539.

[153] M. Lannoy, S. Slove, L. Louedec, C. Choqueux, C. Journé, J.-B. Michel, M.-P. Jacob, Inhibition of ERK1/2 phosphorylation: a new strategy to stimulate elastogenesis in the aorta, Hypertens. Dallas Tex 1979. $64 \quad$ (2014) 423-430. doi:10.1161/HYPERTENSIONAHA.114.03352.

[154] S. Tajima, A. Hayashi, T. Suzuki, T. Nishikawa, Stimulation of elastin expression by minoxidil in chick skin fibroblasts, Arch. Dermatol. Res. 287 (1995) 494-497.

[155] J. Tsoporis, F.W. Keeley, R.M. Lee, F.H. Leenen, Arterial vasodilation and vascular connective tissue changes in spontaneously hypertensive rats, J. Cardiovasc. Pharmacol. 31 (1998) 960-962. doi:10.1097/00005344-199806000-00022.

[156] S. Slove, M. Lannoy, J. Behmoaras, M. Pezet, N. Sloboda, P. Lacolley, B. Escoubet, J. Buján, M.-P. Jacob, Potassium channel openers increase aortic elastic fiber formation and reverse the genetically determined elastin deficit in the BN rat, Hypertens. Dallas Tex 1979. 62 (2013) 794-801. doi:10.1161/HYPERTENSIONAHA.113.01379.

[157] M. Coquand-Gandit, M.-P. Jacob, W. Fhayli, B. Romero, M. Georgieva, S. Bouillot, E. Estève, J.-P. Andrieu, S. Brasseur, S. Bouyon, N. Garcia-Honduvilla, P. Huber, J. Buján, M. Atanasova, G. Faury, Chronic Treatment with Minoxidil Induces Elastic Fiber 
Neosynthesis and Functional Improvement in the Aorta of Aged Mice, Rejuvenation Res. 20 (2017) 218-230. doi:10.1089/rej.2016.1874.

[158] R.H. Knutsen, S.C. Beeman, T.J. Broekelmann, D. Liu, K.M. Tsang, A. Kovacs, L. Ye, J.R. Danback, A. Watson, A. Wardlaw, J.E. Wagenseil, J.R. Garbow, M. Shoykhet, B.A. Kozel, Minoxidil improves vascular compliance, restores cerebral blood flow, and alters extracellular matrix gene expression in a model of chronic vascular stiffness, Am. J. Physiol. Heart Circ. Physiol. 315 (2018) H18-H32. doi:10.1152/ajpheart.00683.2017.

[159] W. Fhayli, M. Boyer, Z. Ghandour, M.P. Jacob, J.P. Andrieu, B.C. Starcher, E. Estève, G. Faury, Chronic administration of minoxidil protects elastic fibers and stimulates their neosynthesis with improvement of the aorta mechanics in mice, Cell. Signal. 62 (2019) 109333. doi:10.1016/j.cellsig.2019.05.018.

[160] S. Raveaud, P. Mezin, N. Lavanchy, B. Starcher, R.P. Mecham, J. Verdetti, G. Faury, Effects of chronic treatment with a low dose of nicorandil on the function of the rat aorta during ageing, Clin. Exp. Pharmacol. Physiol. 36 (2009) 988-994. doi:10.1111/j.14401681.2009.05174.x.

[161] M. Bouhedja, B. Peres, W. Fhayli, Z. Ghandour, A. Boumendjel, G. Faury, S. Khelili, Design, synthesis and biological evaluation of novel ring-opened cromakalim analogues with relaxant effects on vascular and respiratory smooth muscles and as stimulators of elastin synthesis, Eur. J. Med. Chem. $144 \quad$ (2018) 774-796. doi:10.1016/j.ejmech.2017.12.071.

[162] N. Bouider, W. Fhayli, Z. Ghandour, M. Boyer, K. Harrouche, X. Florence, B. Pirotte, P. Lebrun, G. Faury, S. Khelili, Design and synthesis of new potassium channel activators derived from the ring opening of diazoxide: study of their vasodilatory effect, stimulation of elastin synthesis and inhibitory effect on insulin release, Bioorg. Med. Chem. 23 (2015) 1735-1746. doi:10.1016/j.bmc.2015.02.043.

[163] C.M. Halabi, T.J. Broekelmann, R.H. Knutsen, L. Ye, R.P. Mecham, B.A. Kozel, Chronic antihypertensive treatment improves pulse pressure but not large artery mechanics in a mouse model of congenital vascular stiffness, Am. J. Physiol. Heart Circ. Physiol. 309 (2015) H1008-1016. doi:10.1152/ajpheart.00288.2015.

[164] H. Chai, Z. Tao, W. Chen, Y. Xu, F. Huang, C. Su, X. Chen, Cortistatin attenuates angiotensin II-induced abdominal aortic aneurysm through inactivation of the ERK1/2 signaling pathways, Biochem. Biophys. Res. Commun. 495 (2018) 1801-1806. doi:10.1016/j.bbrc.2017.12.033.

[165] S. Sen, S. Bunda, J. Shi, A. Wang, T.F. Mitts, A. Hinek, Retinoblastoma protein modulates the inverse relationship between cellular proliferation and elastogenesis, J. Biol. Chem. 286 (2011) 36580-36591. doi:10.1074/jbc.M111.269944.

[166] V. Cenizo, V. André, C. Reymermier, P. Sommer, O. Damour, E. Perrier, LOXL as a target to increase the elastin content in adult skin: a dill extract induces the LOXL gene expression, Exp. Dermatol. 15 (2006) 574-581. doi:10.1111/j.1600-0625.2006.00442.x.

[167] B. Sohm, V. Cenizo, V. André, H. Zahouani, C. Pailler-Mattei, B. Vogelgesang, Evaluation of the efficacy of a dill extract in vitro and in vivo, Int. J. Cosmet. Sci. 33 (2011) 157-163. doi:10.1111/j.1468-2494.2010.00606.x.

[168] P. Zhang, A. Huang, J. Ferruzzi, R.P. Mecham, B.C. Starcher, G. Tellides, J.D. Humphrey, F.J. Giordano, L.E. Niklason, W.C. Sessa, Inhibition of microRNA-29 enhances elastin levels in cells haploinsufficient for elastin and in bioengineered vessels--brief report, $\begin{array}{llllll}\text { Arterioscler. Thromb. } & \text { Vasc. } & \text { Biol. } & 32 & \text { (2012) }\end{array}$ doi:10.1161/ATVBAHA.111.238113.

[169] P. Zhang, A. Huang, M. Morales-Ruiz, B.C. Starcher, Y. Huang, W.C. Sessa, L.E. Niklason, F.J. Giordano, Engineered zinc-finger proteins can compensate genetic 
haploinsufficiency by transcriptional activation of the wild-type allele: application to Willams-Beuren syndrome and supravalvular aortic stenosis, Hum. Gene Ther. 23 (2012) 1186-1199. doi:10.1089/hum.2011.201.

\section{FIGURE LEGENDS:}

Figure 1: Cellular events and signaling pathways involved in elastic fiber neosynthesis induced by pharmacological treatments.

Application of potassium channel openers to VSMCs leads to cell membrane hyperpolarization and calcium channel blockade. This induces a drop in intracellular $\mathrm{Ca}^{2+}$ concentration and inhibition of the ERK 1/2 pathway, resulting in the activation of the production of mRNAs involved in elastic fiber synthesis (tropoelastin, TE ; fibulin-5, FBLN-5 ; lysyl-oxidase, LOX ; fibrillin-1, FBN-1 ; ...) and secretion of the corresponding proteins. Treatment of the cells with an inhibitor of ERK $1 / 2$ phosphorylation produces the same effect regarding elastin. Elastic fiber neosynthesis then precedes their integration/aggregation into pre-existing elastic fibers and elastic lamellae. Regarding the effect of minoxidil, a limitation of elastic fiber ruptures and AGE formation is also observed.

Figure 2: Evolution of arterial wall structure during development, adulthood, ageing and pharmacotherapy.

During development, elastic fiber deposition takes place in short size arteries, which are later extended by the progressive blood pressure elevation. The extension of elastic fiber leads to the conformation providing them with their normal mechanical properties. During adulthood and aging, cyclic mechanical stress and proteases trigger elastic fiber degradation, leading to failing mechanical properties and increased stiffness. Pharmacological treatments (e.g. minoxidil) in adult or aged mice stimulates the expression of the components allowing for elastic fiber assembly (e.g. tropoelastin, 
fibulin-5 and LOX), and neosynthesized elastic fibers are produced in the media, either aggregated to the pre-existing elastic lamellae (increased thickness of the elastic lamellae) or in the interlamellar spaces (under different orientations). 


\section{Highlights:}

- Elastin and elastic fibers are synthesized only during late pregnancy and childhood

- Elastic fibers provide the arteries with elasticity

- Arterial elasticity allows for smoothing of the pulsatile blood flow and pressure delivered by the heart, leading to appropriate hemodynamics and organ perfusion

- During aging, elastic fibers are altered by mechanical and enzymatic processes, leading to arterial stiffening and dysfunction, altered perfusion and organ damage

- Pharmacological treatments, in particular with the ATP-dependent potassium channel opener minoxidil, reinitiate elastin production in vitro and in vivo

- Minoxidil treatment results in improvements of the arterial mechanics and, at least in aged animals, in neosynthesis of elastic fibers and protection of pre-existing elastic fibers

- Minoxidil and possibly other molecules could be considered as anti-aging agents for the arterial system 
$\mathrm{K}^{+} \Longrightarrow \begin{gathered}\text { Membrane } \\ \text { hyper- }\end{gathered} \quad \mathrm{Ca}^{2+}$

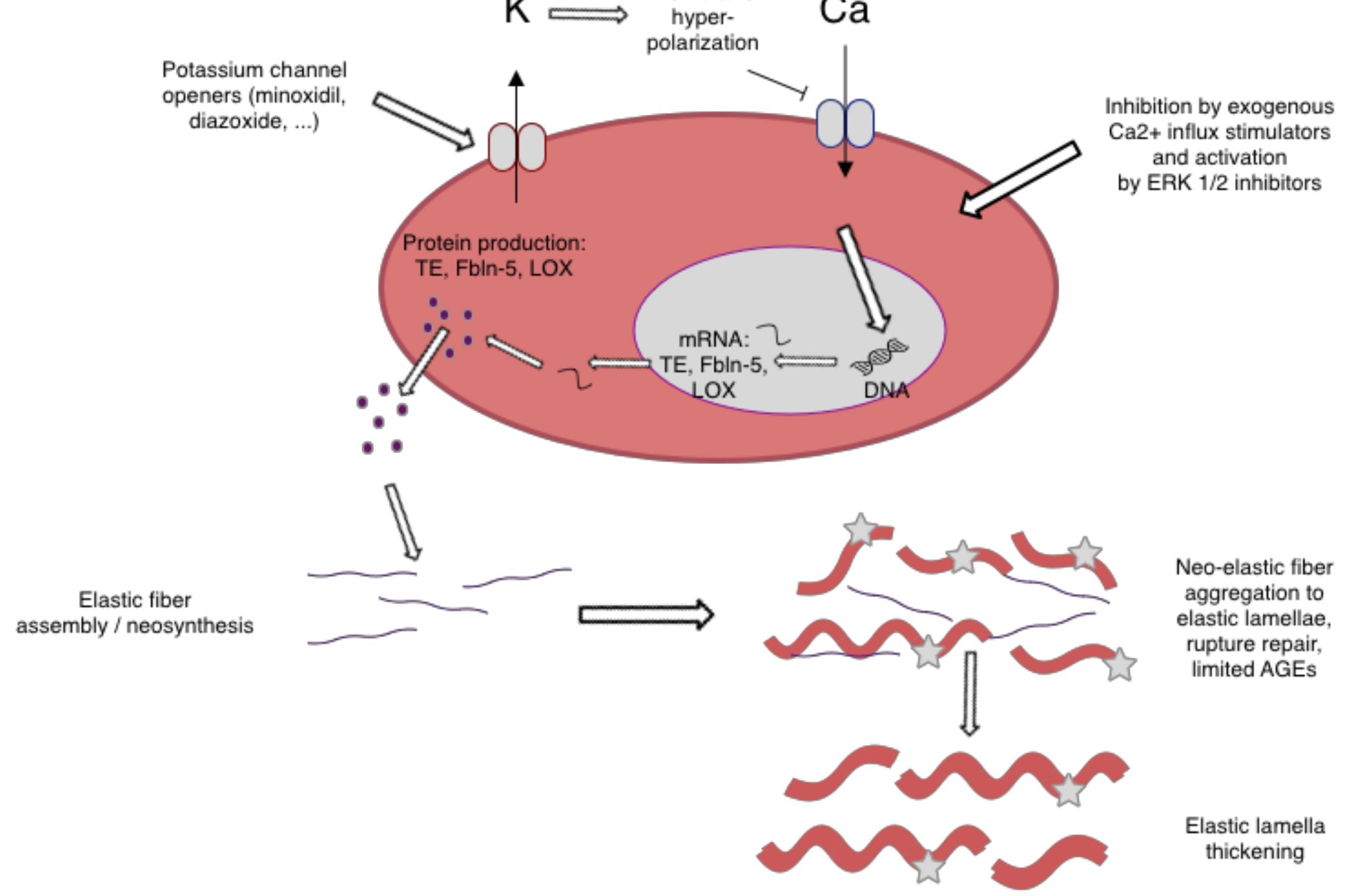

Elastic lamella

Ruptured elastic lamella

Vascular smooth muscle

$\hat{1}$ AGE (bridging fibers)

Neosynthetized elastic fiber

Membrane ion channel 


\section{Growth}


Elastic lamella

Vascular smooth muscle cell

Collagen fiber

Neosynthesized elastic fiber

Q-- Elastase

3 AGE (bridging fibers)

1) Circumferential stretching forces due to blood presure 